\title{
Calcium antagonist drugs in chronic stable angina Comparison of verapamil and nifedipine
}

\author{
J R DAWSON, N H G WHITAKER, G C SUTTON \\ From Hillingdon Hospital, Uxbridge, Middlesex
}

SUMmaRY The relative efficacy of two calcium antagonist drugs, verapamil, $120 \mathrm{mg}$ three times a day and nifedipine, $20 \mathrm{mg}$ three times a day, was examined in a double-blind randomised trial. Patients were assessed at the end of four week periods by a maximal treadmill exercise test, the frequency of anginal attacks, glyceryl trinitrate consumption, and side effects. Sixteen point praecordial maps were recorded at rest, immediately after exercise, and at minute intervals for 10 minutes. Total ST segment depression ( $\mathrm{ST}$ ) was used as a measure of myocardial ischaemia. Both verapamil and nifedipine increased maximal work capacity but $\Sigma S T$ at the termination of the test remained constant. Both drugs reduced the frequency of anginal attacks and glyceryl trinitrate consumption. Systolic blood pressure at rest and on exercise was reduced by both drugs. Verapamil and nifedipine were equally effective in treating angina, but side effects were more common with nifedipine.

Verapamil and nifedipine are effective in the treatment of angina pectoris. ${ }^{1-3}$ Both drugs are described as calcium antagonists because they inhibit the slow calcium current in muscle cells thereby reducing the force of contraction of the myocardium and relaxing smooth muscle. These drugs may therefore be useful in the treatment of angina pectoris either because of a direct reduction in cardiac contractility, ${ }^{4}$ or as a result of the relaxation of vascular smooth muscle causing vasodilatation and afterload reduction, ${ }^{56}$ or through a combination of both mechanisms. Both verapamil ${ }^{7}$ and nifedipine ${ }^{8}$ have been shown to dilate coronary arteries, possibly resulting in increased myocardial oxygen supply, though in the case of nifedipine this view has been challenged. ${ }^{9}$ The relative effects on cardiac contractility, afterload reduction, and coronary vasodilatation of the two drugs have not been determined with certainty. A point of difference is that verapamil, but not nifedipine, has antiarrhythmic properties depressing atrioventricular node function. ${ }^{10}$ Though these drugs have certain pharmacological similarities as well as differences, the clinical relevance in the treatment of patients with angina has not been established. This study was designed to make a direct comparison using exercise testing as an objective assessment.

Received for publication 14 May 1981

\section{Patients and methods}

Studies were carried out on 16 patients, 15 men and one woman, mean age 56 years (range 43 to 69 years) with stable angina. All patients had frequent attacks of stress-induced chest pain occurring in a constant and predictable pattern for at least six months, in spite of treatment with beta-adrenergic blocking drugs and nitrites. No patient had a history of myocardial infarction, heart failure, or atrioventricular conduction abnormalities within the previous year. Seven patients had had a myocardial infarct, documented by the electrocardiogram and enzyme changes, before this period. Before entry to the study, each patient had been shown to have an unequivocally abnormal exercise test.

The trial was double-blind and randomised. Patients gave verbal consent. Patient compliance was checked by tablet counting. A "double dummy" technique was employed so that at all times the drugs appeared visually identical. Before starting the trial, each patient was withdrawn slowly from previous treatment. For two weeks patients received no treatment other than glyceryl trinitrate. The three treatment periods, each of four weeks and in random sequence, were: verapamil, $120 \mathrm{mg}$, nifedipine, 20 $\mathrm{mg}$, both three times a day (the latter $10 \mathrm{mg}$ three 
times a day for the first three days), and placebo. Forty-eight hours without any treatment was allowed between each treatment period and at the end of each the following assessments were made:

(1) A maximal exercise test using the Bruce protocol. ${ }^{11}$ The electrocardiogram was recorded from 16 praecordial leads. ${ }^{12}$ The patients did not smoke or take glyceryl trinitrite in the two hours before the test. For each patient the test was performed at the same time of day and with the same relation to meals.

(2) The number of anginal attacks during each four week period.

(3) Glyceryl trinitrate consumption during the four weeks. Both two and three were assessed from diaries kept by the patient.

(4) Side effects were recorded. A questionnaire monitoring 43 potential side effects using an analogue scale was completed by each patient on days 7 and 28 of each treatment period.

TECHNIQUE AND MEASUREMENT OF EXERCISE TESTS Exercise was performed on a treadmill (Quinton Instruments Model 18/54) following the Bruce protocol. Patients were exercised until symptoms (chest pain and/or dyspnoea) forced them to stop. Estimated maximal oxygen uptake $\left(\mathrm{VO}_{2} \mathrm{max}\right)$ was calculated from the duration of exercise on the treadmill, according to the method of Bruce et al., ${ }^{13}$ and was used as a measure of work capacity. The randomisation of treatment periods obviated a training effect. Patients had been familiarised previously with the exercise test.

Sixteen point praecordial electrocardiograms were recorded with the patient in a sitting position before exercise and at $0,1,2,3,4,5,7$, and 10 minutes after exercise. The electrodes were placed in a 4 by 4 grid over the left hemithorax. The boundaries of the grid were the second intercostal space superiorly, a line drawn horizontally $6 \mathrm{~cm}$ beneath the xiphisternum inferiorly, the left mid-axillary line, and the right sternal edge. Each tracing was analysed by an observer before the treatment code was broken, thereby excluding observer bias. Significant ST segment depression was considered to exist if there was a change of $1.0 \mathrm{~mm}$ or more, lasting for $0.08 \mathrm{~s}$ or longer. ${ }^{14}$ Measurements of ST segment depression to the nearest $0.5 \mathrm{~mm}$ were made on three complexes for each praecordial point and the average taken. For each recording the sum of significant ST segment depression ( $\Sigma S T$ ) was calculated and used as an index of myocardial ischaemia. Resting and maximum exercise-induced heart rate were recorded. Systolic blood pressure was measured at rest and at minute intervals throughout exercise and the recovery period.

\section{Results}

Results are expressed as mean \pm SEM and were compared using Student's paired t test.

\section{ANGINAL ATTACKS}

Compared with placebo, both verapamil $(p<0.01)$
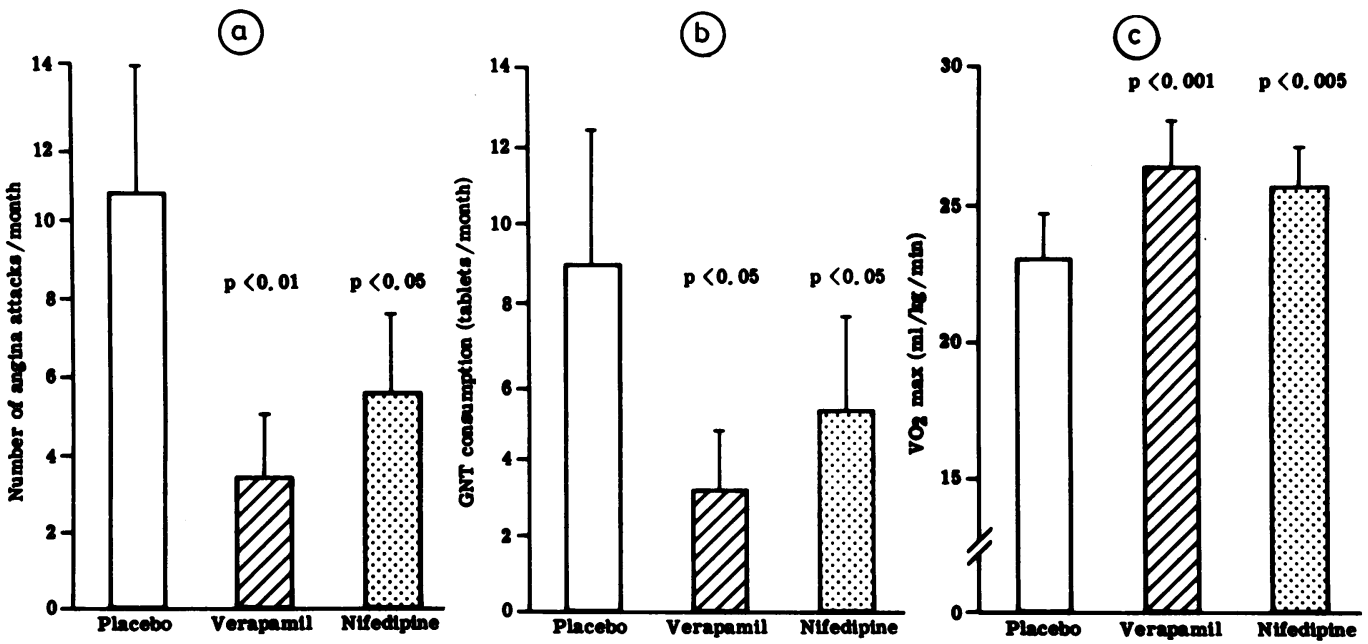

Fig. 1 From left to right (a) the number of attacks of angina per month in each treatment group, (b) glyceryl trinitrate consumption, and (c) maximal work capacity achieved (expressed as $\mathrm{VO}_{2}$ max) at the end of each treatment period. 
and nifedipine $(p<0.05)$ significantly decreased the frequency of anginal attacks (Fig. 1a).

GLYCERYL TRINITRATE CONSUMPTION

Both drugs reduced glyceryl trinitrate consumption compared with placebo $(p<0.05)$ (Fig. lb).

\section{MAXIMAL WORK CAPACITY}

In the placebo period maximal work capacity, expressed as $\mathrm{VO}_{2} \max$, was $22.9 \pm 1.5 \mathrm{ml} / \mathrm{kg}$ per min. Both drugs increased this value; verapamil to $26 \pm 1 \cdot 4$ $\mathrm{ml} / \mathrm{kg}$ per $\min (\mathrm{p}<0.001)$ and nifedipine to $25 \cdot 2 \pm 1 \cdot 5$ $\mathrm{ml} / \mathrm{kg}$ per $\min (\mathrm{p}<0.005)$ (Fig. lc).

There was no significant difference in the effect on anginal attacks, glyceryl trinitrate consumption, and maximal work capacity between nifedipine and verapamil.

\section{SYSTOLIC BLOOD PRESSURE}

Resting systolic blood pressure was significantly reduced by both drugs. The control value of $147 \pm 5$ $\mathrm{mmHg}$ was reduced by verapamil to $132 \pm 4 \mathrm{mmHg}$ $(\mathrm{p}<0.005)$ and by nifedipine to $127 \pm 10 \mathrm{mmHg}$ $(\mathrm{p}<0.01)$.

The control value for maximal exercise-induced systolic blood pressure of $200 \pm 7 \mathrm{mmHg}$ was reduced by nifedipine to $187 \pm 4 \mathrm{mmHg}(\mathrm{p}<0.05)$, and by verapamil to $192 \pm 5 \mathrm{mmHg}$ (not significant).

The systolic blood pressure for a given work load (the work capacity achieved during the control period) was significantly reduced by both drugs from the control value of $200 \pm 7 \mathrm{mmHg}$. Verapamil reduced the systolic blood pressure to $173 \pm 7 \mathrm{mmHg}$ $(\mathrm{p}<0.005)$ and nifedipine reduced it to $168 \pm 6 \mathrm{mmHg}$ $(\mathrm{p}<0.001)$.

\section{HEART RATE}

Verapamil produced a small but significant reduction in resting heart rate from $72 \pm 3$ beats $/ \mathrm{min}$ to $68 \pm 2$ beats $/ \mathrm{min}(\mathrm{p}<0.05)$, whereas nifedipine tended to increase resting heart rate to $76 \pm 4$ beats/min (not significant). The maximal exercise-induced heart rate of $122 \pm 5$ beats $/ \mathrm{min}$ was reduced by verapamil to $118 \pm 4$ beats/min (not significant) and was increased by nifedipine to $132 \pm 4$ beats/min $(p<0.05)$.

\section{ST SEGMENT CHANGES}

Fig. 2 shows the changes in $\Sigma S T$ with respect to time in the three treatment periods. $\Sigma S T$ is maximal immediately, or soon after, exercise and gradually regresses to pre-exercise values after 10 minutes of recovery. Though there is a considerable increase in $\mathrm{VO}_{2} \mathrm{max}$ (that is increased exercise performance), ¿ST (the "amount of myocardial ischaemia") in the verapamil and nifedipine treatment periods is unchanged from control values at all times.

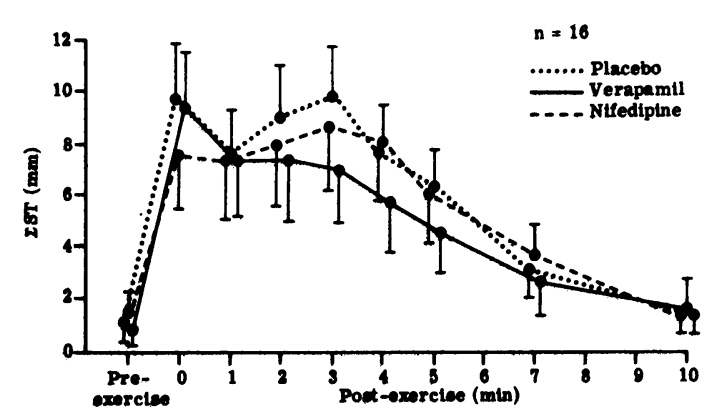

Fig. 2 Changes in $\Sigma S T$ with time, after maximal exercise, at the end of each treatment period.

SIDE EFFECTS

Patients graded each side effect by marking along a $100 \mathrm{~mm}$ scale. Side effects which were marked more than $10 \mathrm{~mm}$ different from the value in the control month were considered to be significant. In each treatment period, side effects were more frequently recorded at seven days than at 28 days. Side effects were most frequent in the nifedipine treatment period. Pain and swelling of the ankles were recorded by five patients when taking nifedipine and by only one when taking verapamil. Six patients complained of palpitation only when taking nifedipine. Five patients taking nifedipine and three taking verapamil complained of indigestion. Constipation (seven patients) was the principal side effect reported during the verapamil treatment period whereas only one patient complained of constipation while taking nifedipine.

\section{Discussion}

ST segment maps record the electrocardiographic manifestations of myocardial ischaemia that are projected onto the praecordium. The technique is reproducible, ${ }^{15}$ demonstrating the development of an area of ischaemia which is maximal immediately, or soon after, exercise and which gradually regresses during recovery from exercise. The sum of ST segment depression ( $\ S$ T) at 16 praecordial points can be calculated and used to assess the severity of ischaemia. The technique can be used to evaluate treatment of myocardial ischaemia either by the demonstration of an improved work capacity or by showing reduced ischaemia for a given work load.

Our results show that both verapamil and nifedipine significantly increase work capacity (measured as $\mathrm{VO}_{2}$ max calculated from the duration of exercise on the treadmill) without changing the amount of myocardial ischaemia developed (as assessed by $\Sigma S T$ ). After completion of the trial 
protocol, eight patients were given verapamil for one week and then exercised to the same work load as they achieved in the control period in the trial. The result (Fig. 3) illustrates that verapamil reduced the amount of ischaemia developed when the work load was fixed. Both drugs were found to reduce the frequency of anginal attacks and glyceryl trinitrate consumption. Systolic blood pressure, both at rest and when exercising to a given work load, was much reduced by both drugs. This agrees with previous studies on the haemodynamic effects of verapamil ${ }^{5}$ and nifedipine. ${ }^{6}$ It may explain the striking beneficial effects of both drugs, as afterload reduction enables the heart to use its available oxygen supply in performing useful volume work rather than energy consuming pressure work. ${ }^{16}$

The effect of the two drugs on heart rate differed; nifedipine produced small rises in resting and maximal exercise-induced heart rate whereas verapamil tended to reduce both values. A fall in systolic blood pressure is normally accompanied by a reflex increase in heart rate, as was observed with nifedipine. Though verapamil produced a similar fall in systolic blood pressure to nifedipine, the expected reflex tachycardia was not observed. This suggests that verapamil, in contrast to nifedipine, has an additional negative chronotropic action that blocks the normal reflex increase in heart rate in response to a fall in systolic blood pressure.

The results show that side effects with nifedipine occur frequently. The most frequently recorded complaints were palpitation, pain in and swelling of the ankles, and indigestion. In contrast, verapamil was relatively free from side effects apart from constipation which was described by seven patients. Verapamil was not observed to prolong the PR interval in our patients. This well-recognised effect, however, is a contraindication to its use in conjunction with a beta-blocking agent in the treatment of supraventricular tachycardias ${ }^{17}$ and is therefore

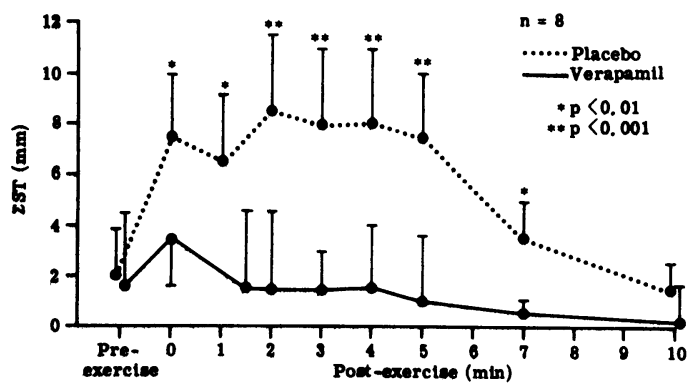

Fig. 3 Changes in $\Sigma S T$ with time after exercising to a fixed work load, in eight patients taking verapamil, compared with placebo. potentially a major limitation to its usefulness in the treatment of angina. Nifedipine, in contrast, has been shown to be both safe and efficacious when used in conjunction with propranolol in the treatment of angina. ${ }^{18}$

This study shows that both verapamil and nifedipine produce substantial benefit in the treatment of chronic stable angina. Though it can safely be used in conjunction with a beta-blocker, the high incidence of side effects with nifedipine limits its clinical usefulness, suggesting that verapamil may be the drug of choice when a calcium antagonist is to be used alone. A major reservation, however, is that it is not yet established that verapamil can be used safely in conjunction with a beta-blocking agent for the treatment of angina.

The authors thank Dr A Selwyn for advice and criticism, and Abbott Laboratories Ltd and Bayer (UK) Ltd for supplies of verapamil and nifedipine.

\section{References}

1 Balasubramanian V, Khanna PK, Narayanan GR, Hoon RS. Verapamil in ischaemic heart disease - quantitative assessment by serial multistage treadmill exercise. Postgrad Med F 1976; 52: 143-7.

2 Jatene AD, Lichtlen PR. 3rd International Adalat symposium. New therapy of ischaemic heart disease. (International Congress Series No 388.) Amsterdam: Excerpta Medica, 1976: 388.

3 De Ponti C, Mauri F, Ciliberto GR, Carù B. Comparative effects of nifedipine, verapamil, isosorbide dinitrate and propranolol on exercise-induced angina pectoris. Eur f Cardiol 1979; 10: 47-58.

4 Fleckenstein A, Doring H-J, Janke J, Byon Y K. Basic action of ions and drugs on myocardial high-energy phosphate metabolism and contractility. In: Schmier JS, Eichler O, ed. Handbook of experimental pharmacology. Berlin: Springer-Verlag, 1975: 345-405.

5 Atterhög JH, Ekelund LG. Haemodynamic effects of intravenous verapamil at rest and during exercise in subjectively healthy middle-aged men. Eur $\mathcal{f}$ Clin Pharmacol 1975; 8: 317-22.

6 Lydtin H, Lohmoller R, Schmitz H, Walter I. Haemodynamic studies on adalat in healthy volunteers and in patients. In: Lochner W, Braasch W, Kroneberg G, eds. (2nd International Adalat symposium.) New therapy of ischaemic heart disease. Berlin: Springer, 1975: 112.

7 Simonsen S. Effect of verapamil on coronary hemodynamics in patients with coronary heart disease. Eur $\mathcal{F}$ Cardiol 1978; 8: 9-18.

8 Lichtlen PR, Engel HJ, Amende L, Rafflenbenl W, Simon $R$. Mechanism of various antianginal drugs. Relationship. between regional flow behaviour and contractility. In: Jatene AD, Lichtlen PR, eds. 3rd International Adalat symposium. New therapy of ischaemic heart disease. Amsterdam: Excerpta Medica, 1976: 14 29. 
9 Kaltenbach M, Schulz W, Kober G. Effects of nifedipine after intravenous and intracoronary administration. $A m \mathcal{F}$ Cardiol 1979; 44: 832-8.

10 Rowland E, Evans T, Krikler D. Effects of nifedipine on atrioventricular conduction as compared with verapamil. Br Heart F 1979; 42: 124-7.

11 Bruce RA. Exercise testing of patients with coronary heart disease. Principles and normal standards for evaluation. Ann Clin Res 1971; 3: 323-32.

12 Fox KM, Selwyn AP, Shillingford JP. A method for praecordial surface mapping of the exercise electrocardiogram. Br Heart $\mathcal{F}$ 1978; 40: 1339-43.

13 Bruce RA, Kusumi F, Hosmer D. Maximal oxygen uptake and nomographic assessment of functional aerobic impairment in cardiovascular disease. Am Heart f 1973; 85: 546-62.

14 Myers GB, Talmers FR. The electrocardiographic diagnosis of acute myocardial ischemia. Ann Intern Med 1955; 43: 361-82.

15 Fox K, Selwyn A, Oakley D, Jonathan A, Shillingford J. Praecordial surface mapping after exercise in evaluation of propranolol for angina pectoris. $\mathrm{Br}$ Heart $\mathcal{F}$ 1980; 43: 376-81.

16 Braunwald E. Control of myocardial oxygen consumption. Am $\mathcal{F}$ Cardiol 1971; 27: 416-32.

17 Krikler D. Verapamil in cardiology. Eur $\mathcal{F}$ Cardiol 1974; 2: 3-10.

18 Lynch P, Dargie H, Krikler S, Krikler D. Objective assessment of antianginal treatment: a double-blind comparison of propranolol, nifedipine, and their combination. Br Med F 1980; 281 : 184-7.

Requests for reprints to Dr G C Sutton, Hillingdon Hospital, Uxbridge, Middlesex UB8 3NN. 